\title{
Onde as religiões se encontram: um estudo de representações sociais das drogas psicoativas e suas implicações para no cuidado em enfermagem
}

Where religions meet: a study of social representations of psychoactive drugs and their implications for nursing care

Donde las religiones se encuentran: un estudio de las representaciones sociales de las drogas psicoactivas y sus implicaciones para el cuidado de enfermería

Recebido: 07/12/2020 | Revisado: 14/12/2020 | Aceito: 05/01/2021 | Publicado: 06/01/2021

$$
\begin{array}{r}
\text { Diogo Jacintho Barbosa } \\
\text { ORCID: https://orcid.org/0000-0001-8816-1770 } \\
\text { Universidade do Estado do Rio de Janeiro, Brasil } \\
\text { E-mail: jacinthobarbosa @ gmail.com } \\
\text { Antônio Marcos Tosoli Gomes } \\
\text { ORCID: https://orcid.org/0000-0003-4235-9647 } \\
\text { Universidade do Estado do Rio de Janeiro, Brasil } \\
\text { E-mail: mtosoli @ gmail.com } \\
\text { Marcia Pereira Gomes } \\
\text { ORCID: https://orcid.org/00-0002- 7872-5891 } \\
\text { Hospital dos Servidores do Estado do Rio de Janeiro, Brasil } \\
\text { E-mail:mpsemog @ gmail.com } \\
\text { Lívia Maria da Silva Gonçalves } \\
\text { ORCID: https://orcid.org/0000-0003-2337-2547 } \\
\text { Universidade Federal da Bahia, Brasil } \\
\text { E-mail:liviajeje @yahoo.com }
\end{array}
$$

\begin{abstract}
Resumo
Os objetivos do estudo foram identificar os pontos de conjunção a respeito das representações sociais das drogas psicoativas para os grupos religiosos católicos, evangélicos, umbanda, candomblé e espírita e analisar a influência dessas representações na inclusão da espiritualidade e da religiosidade nas práticas de cuidado nas áreas da saúde e da enfermagem. Este estudo descritivo, foi desenvolvido a partir de uma abordagem com método misto exploratória sequencial. Participaram deste estudo 1.400 sujeitos, divididos em sete grupos sociais, cada um com 200 participantes. Assim, quando analisamos o conjunto de resultados, podemos observar que, de maneira geral, as representações sociais aqui encontradas perpassam em cada religião, pelas doutrinas religiosas e pelo conhecimento dos seus fiéis sobre o assunto, de modo a entender as implicações para cada religião, a fim de se propor um cuidado em saúde e em enfermagem que vise alcançar o ser humano em sua plenitude como um ser biopsicossocial-espiritual.
\end{abstract}

Palavras-chave: Drogas psicoativas; Enfermagem; Religião; Espiritualidade.

\begin{abstract}
The objectives of the study were to identify the points of conjunction regarding social representations of drugs for Catholic, Evangelical, Umbanda, Candomblé and Espirita religious groups and Analyze the influence of these representations in the inclusion of spirituality and religiosity in care practices in health and nursing. This descriptive study was developed from a mixed exploratory sequential approach. 1,400 subjects participated in this study, divided into seven social groups, each with 200 participants. Thus, when we analyze the set of results, we can observe that, in general, the social representations found here permeate each religion, religious doctrines and the knowledge of its faithful on the subject, in order to understand the implications for each religion, in order to propose health and nursing care that aims to reach the human being in its fullness as a biopsychosocial-spiritual being.
\end{abstract}

Keywords: Psychoactive drugs; Nursing; Religion; Spirituality.

\section{Resumen}

Los objetivos del estudio fueron identificar los puntos de conjunción de las representaciones sociales de las drogas para los grupos religiosos católicos, evangélicos, umbanda, candomblé y espirita y analizar la influencia de estas representaciones en la inclusión de la espiritualidad y religiosidad en las prácticas asistenciales en salud y enfermería. Este estudio descriptivo se desarrolló a partir de un enfoque secuencial exploratorio mixto. 1.400 sujetos participaron en este estudio, divididos en siete grupos sociales, cada uno con 200 participantes. Así, cuando analizamos el conjunto de resultados, podemos observar que, en general, las representaciones sociales aquí encontradas permean cada religión, doctrinas religiosas y el conocimiento de sus fieles sobre el tema, con el fin de comprender las implicaciones 
para cada religión, en con el fin de proponer cuidados de salud y de enfermería que tengan como objetivo llegar al ser humano en su plenitud como ser biopsicosocial-espiritual.

Palabras clave: Psicoactivos; Enfermería; Religión; Espiritualidad.

\section{Introdução}

Este estudo versa sobre as representações sociais das drogas psicoativas e de seus usuários para grupos religiosos, trata-se de um recorte feito a partir da tese de doutorado apresentada ao Programa de Pós-graduação da Faculdade de Enfermagem Universidade do Estado do Rio de Janeiro.

O uso de drogas psicoativas existe desde o princípio da história do homem e, diversos fatores estão atrelados ao início, à manutenção e à continuação da sua utilização, dentre os quais se destacam: curiosidade, desejo de transcendência e as buscas pela imortalidade, pelo prazer e pela sabedoria (Teixeira, Engstrom, \& Ribeiro, 2017). Estima-se que um total de 246 milhões de pessoas - um pouco mais que 5\% da população mundial com idade entre 15 e 64 anos - tenham feito uso de drogas ilícitas em 2013(Silva, 2012).

O reconhecimento da utilização das drogas psicoativas como um problema de saúde pública levou a uma reformulação no modelo de tratamento empregado pelas unidades de saúde, denominada Reforma Psiquiátrica. Esse novo modelo de cuidado se apoiou em um novo conceito de saúde, conceito este que perpassa pela definição de cuidado integral, que visa não somente alcançar o ser humano no que tange às suas doenças, como ainda seu social e seu mental (Braga, 2020).

Logo, o modelo de cuidado integral é capaz de alcançar o ser humano nas diversas esferas que compõem sua vida. Esse conceito ainda perpassa pela definição do ser humano como biopsicossocial-espiritual, capaz de se posicionar diante dos condicionantes, no qual este é confrontado com uma ação específica, e a forma com que este responde aos enfrentamentos o torna um ser único (Castaneda, 2019).

Percebemos que a dimensão espiritual dá ao ser humano a capacidade de existir e não apenas de sobreviver. Entender a necessidade da implantação de um cuidado biopsicossocial-espiritual é compreender o ser humano como integral e projetar isso no cuidado em saúde, contemplando outras dimensões no cuidado não só da doença, o que nos faz considerar a inserção da religiosidade e da espiritualidade no cuidado (Barbosa, Tosoli, Soares, \& Paes, 2018).

No Brasil, é possível observar o grande número de pessoas adeptas às diversas religiões, o que se classifica como algo diversificado e caracterizado pelo sincretismo (Alves, Cavenaghi, Barros, \& Carvalho, 2017) ${ }^{6}$. A constituição brasileira prevê a liberdade de religião e deixa claro a existente separação entre religião e o Estado, configurando o país como um Estado laico.

Segundo dados divulgados em 2010, em um Censo realizado pelo Instituto Brasileiro de Geografia e Estatística (IBGE), 91\% dos brasileiros residentes na região Sudeste se declaram adeptos a alguma religião, e as religiões que apresentam expressão nessa região são: católica apostólica romana (59,5\%), evangélicos (24,6\%), espíritas $(3,1 \%)$, umbanda e candomblé $(0,4 \%)$ e outras religiões $(3,4 \%)$ (IBGE,2010).

Dessa forma, questionou-se quais os pontos de encontro entre as principais religiões no Brasil a partir do olhar das representações sociais das drogas psicoativas das quais as implicações para o cuidar em saúde e enfermagem. Para responder a esta pergunta de pesquisa, foram traçados os seguintes objetivos: identificar os pontos de conjunção a respeito das representações sociais das drogas psicoativas para os grupos religiosos católicos, evangélicos, umbanda, candomblé e espírita e analisar a influência dessas representações na inclusão da espiritualidade e da religiosidade nas práticas de cuidado nas áreas da saúde e da enfermagem.

De modo a facilitar a compreensão deste estudo, julgou-se necessário a definição de Teoria das Representações Sociais (TRS). Essa teoria elaborada por Serge Moscovici, tem como objetivo a explicação dos fenômenos sociais sob o ponto de vista coletivo, sem que seja esquecida a perspectiva individual (Moscovici, 2001). 


\section{Metodologia}

Este estudo descritivo, foi desenvolvido a partir de uma abordagem com método misto. Esse tipo de metodologia nos permite analisar, com grau de precisão, os resultados de um instrumento considerando os mecanismos da pesquisa quantitativa e qualitativa ao mesmo tempo, nos permite entender e compreender um fenômeno no local em que ele acontece (Farias Filho, Marchisotti, Maggessi, \& Miranda Junior, 2018). Esse tipo de abordagem é utilizado em diversos estudos na área da saúde, uma vez que essas abordagens distintas se completam.

Dessa forma, este estudo foi desenvolvido a partir da estratégia de métodos mistos, denominada como exploratória sequencial, na qual são coletados e analisados em uma primeira etapa de pesquisa os dados qualitativos seguida de coleta e análise de dados quantitativos desenvolvida sobre os resultados qualitativos iniciais (Farias Filho et al.,2018), caracterizando, assim, o estudo como quali-quantitativo. Dessa forma, daremos maior peso à parte qualitativa do estudo que compreende a análise prototípica.

Apresentaremos neste artigo um recorte apenas dos resultados atrelados à análise prototípica, haja vista, que este resultado favorece um olhar amplo e geral a cerca dos resultados, permitindo-nos analisar do ponto de vista da teoria das representações sociais e fazer inferências acerca das implicações para o cuidar em saúde e em enfermagem.

O cenário de coleta de dados foi os templos religiosos dos seguintes grupos: católicos, evangélicos de três segmentos distintos, quais sejam, históricos, pentecostais e neopentecostais, religiões de matriz africana (umbanda e candomblé) e espíritas (kardecistas). A escolha por esses grupos religiosos se deu tendo em vista o Censo demográfico realizado pelo IBGE, que os apontou como os que apresentavam o maior número de fiéis no estado do Rio de Janeiro.

Os participantes do estudo foram fiéis dos grupos religiosos aqui apresentados. O critério de seleção da amostra foi amostra do tipo não probabilística por conveniência, composta pelos grupos religiosos com maior número de fiéis no Rio de Janeiro, com base no Censo Demográfico do IBGE de 2010.

Os participantes foram abordados em seus respectivos templos religiosos, após a participação em atividades cúlticas ou ritualísticas. Os critérios de inclusão foram idade igual ou superior a 18 anos e frequentar a comunidade religiosa em questão há, pelo menos, seis meses. Para a participação no estudo, além de preencher os critérios de inclusão, foi necessário que os sujeitos assinassem o Termo de Consentimento Livre e Esclarecido, de modo a contemplar os aspectos éticos da pesquisa com seres humanos.

A amostra final deste estudo foi composta por 1.400 participantes e a distribuição dos participantes pelos grupos religiosos pode ser observado no Quadro 1.

Quadro 1. Distribuição dos sujeitos participantes da primeira etapa de coleta de dados de acordo com a religião.

\begin{tabular}{|l|l|}
\hline Religiões & $\begin{array}{l}\text { Questionário sócio-econômico-cultural } \\
\text { Evocação Livre } \\
\text { Escala de Religiosidade }\end{array}$ \\
\hline Católica & 200 \\
\hline Evangélicos Históricos & 200 \\
\hline Evangélicos Pentecostais & 200 \\
\hline $\begin{array}{l}\text { Evangélicos } \\
\text { Neopentecostais }\end{array}$ & 200 \\
\hline Candomblé & 200 \\
\hline Umbanda & 200 \\
\hline Espírita (Kardecista) & 200 \\
\hline Total & 1400 \\
\hline
\end{tabular}

Fonte: Autores (2020). 
A coleta de dados foi realizada a partir da Evocação Livre de Palavras este é um tipo de investigação aberta, baseada na evocação das respostas dos entrevistados a partir de um ou de mais estímulos, capazes de induzir pensamentos sobre uma determinada temática. A Evocação Livre de Palavras ainda permite evidenciar universos semânticos de palavras agrupadas por determinados grupos. Esse método de coleta de dados tem-se mostrado útil nos estudos de estereótipos, de percepções e de atitudes, que são elementos da estrutura e/ou da organização das representações sociais (Santos et al.,2020).

A pesquisa foi desenvolvida em conformidade com as Resoluções 466/12 e 510/16 do Conselho Nacional da Saúde, tendo sido aprovada pelo comitê de ética em pesquisa sob o parecer nº 3.121.454 e CAAE 06246419.7.1001.8144.

\section{Resultados}

Participaram deste estudo 1.400 sujeitos, divididos em sete grupos sociais, cada um com 200 participantes, conforme demonstrado no Quadro 1. Dessa forma, foram selecionadas algumas variáveis pertinentes ao estudo de modo a analisar a relação com o objeto. Os dados foram submetidos à estatística simples, de maneira a facilitar a compreensão do estudo.

Dentre os 1.400 participantes, 1.025 (73\%) eram do sexo feminino e 375 (27\%), do sexo masculino. Esses dados coadunam com os divulgados pelo Censo do IBGE (2010), segundo os quais, no Rio de Janeiro, o número de habitantes mulheres, a partir dos 18 anos, é maior que o número de homens.

A respeito da idade dos participantes, foi possível observar uma predominância de pessoas com idade entre 31 e 40 anos. Nos estudos sobre religião e sobre saúde, a idade mostrou-se um fator diretamente relacionado à frequência nos templos religiosos. Neste estudo, foi observado que quanto maior a idade apresentada pelo indivíduo, maior a sua frequência nos templos religiosos (Richter Reimer \& Lemos, 2020).

O Quadro 2 demostra os resultados da primeira etapa do estudo, elaborada a partir do teste de evocação livre das palavras, onde foi possível identificar os prováveis elementos considerados centrais para cada grupo religioso no tocante ao termo indutor drogas. Dessa forma, as palavras apresentadas no Quadro 2 demonstram o significado representacional das drogas para cada grupo religioso pesquisado.

A partir da identificação destes elementos, foi possível observar os pontos de conjunção entre as religiões a respeito das representações sociais.

Quadro 2. Distribuição dos elementos positivos e negativos do provável núcleo central para os grupos religiosos. Termo indutor: drogas. Rio de Janeiro, RJ, Brasil, 2020.

\begin{tabular}{|l|l|l|l|l|l|}
\hline \multicolumn{7}{|c|}{ Termo indutor: Drogas } \\
\hline Católico & Raiva (-) & Família (+) & Dependência (-) & Ofensa (-) & $\begin{array}{l}\text { Fraqueza } \\
(-)\end{array}$ \\
\hline $\begin{array}{l}\text { Evangélicos } \\
\text { Históricos }\end{array}$ & Destruição (-) & Vício (-) & Dependência (-) & Morte (-) & - \\
\hline $\begin{array}{l}\text { Evangélicos } \\
\text { Pentecostais }\end{array}$ & Destruição (-) & Vício (-) & Dependência (-) & - & - \\
\hline $\begin{array}{l}\text { Evangélicos } \\
\text { Neopentecostais }\end{array}$ & Destruição (-) & $\begin{array}{l}\text { Tratamento } \\
(+)\end{array}$ & Dependência (-) & - & - \\
\hline Umbanda & Tristeza (-) & Doença (-) & Dependência (-) & - & - \\
\hline Candomblé & Tristeza (-) & Droga (-) & Dependência (-) & $\begin{array}{l}\text { Destruição } \\
(-)\end{array}$ & - \\
\hline Espírita & Tristeza (-) & Doença (-) & Dependência (-) & - & - \\
\hline
\end{tabular}

Legenda: ${ }^{*}$ =200 para cada grupo religioso. Fonte: Universidade Federal Rural do Rio de Janeiro, Brasil. 
O Quadro 2 deixa claro que a provável representação social acerca das drogas psicoativas se permeia por elementos de conotação negativa, culminando em uma imagem nociva desses grupos religiosos a respeito da droga.

Nos prováveis núcleos centrais, podemos observar pontos de ligação entre os grupos religiosos participantes do estudo. Observa-se que entre os grupos religiosos de católicos, de evangélicos (históricos, pentecostais e neopentecostais), de religiões de matriz africana (umbanda e candomblé) e de espíritas, a respeito do termo indutor "drogas", o ponto de conjunção é o elemento "dependência", o que nos remete a noções de causalidade e de doença, como demonstrado na Figura 1.

Essa relação de causa e efeito pode ser explicada pela teoria comportamental de dependência de drogas como escolha os indivíduos escolhem supervalorizar o consumo de drogas em detrimento de outras atividades. Muitas pessoas utilizam essa ideia de "supervaloração" em suas escolhas diárias, o que nem sempre lhes traz boas (Mariano, Oliveira, \& Babachinas, 2020).

Figura 1. Ponto de conjunção entre os grupos religiosos participantes do estudo com base nos prováveis núcleos centrais do termo indutor drogas. Rio de Janeiro, RJ, Brasil, 2020.

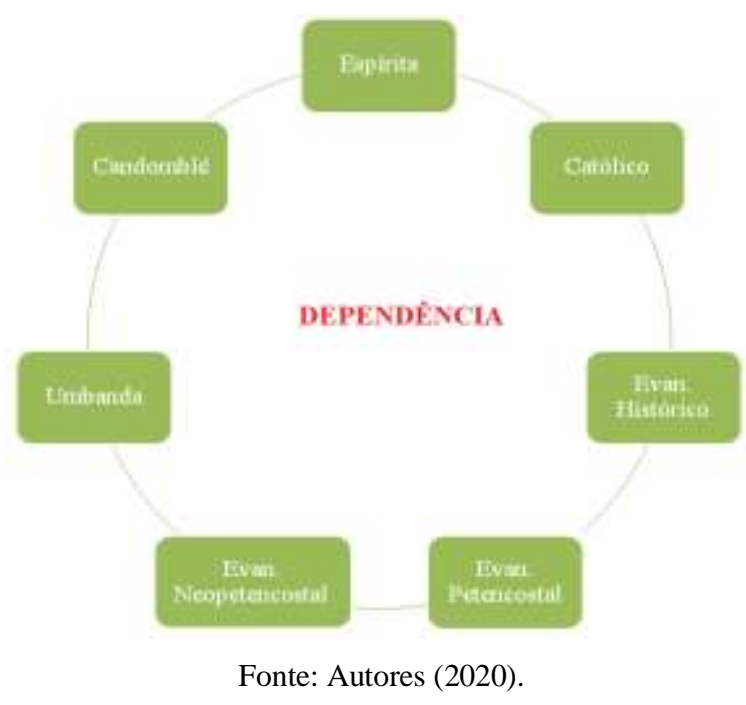

Atualmente, a dependência de drogas é vista como doença e descrita no DSM-V (Manual de Diagnóstico de Transtornos Mentais), e o elemento doença vem sendo substituído por transtorno (Juruena, 2017). No entanto, acerca das religiões, a dependência ainda é vista como no século XIX, quando os usuários de drogas eram considerados como "pecaminosos", indecentes e pessoas sem caráter que tinham como escolha ingerir ou não a droga e escolhiam a ingestão. Em todas as religiões pertencentes ao estudo, a dependência era vista como um fator capaz de causar separação entre o usuário e o divino.

Quando comparamos as religiões católica e espírita, observamos o elemento "dependência" como ponto de conjunção, como descrito anteriormente, o que reforça a noção de causalidade, encontrada na análise da conjunção geral dos grupos religiosos, o que pode ser observado na Figura 2. 
Figura 2. Ponto de conjunção entre os grupos religiosos católicos e espíritas com base nos prováveis núcleos centrais do termo indutor drogas. Rio de Janeiro, RJ, Brasil, 2020.

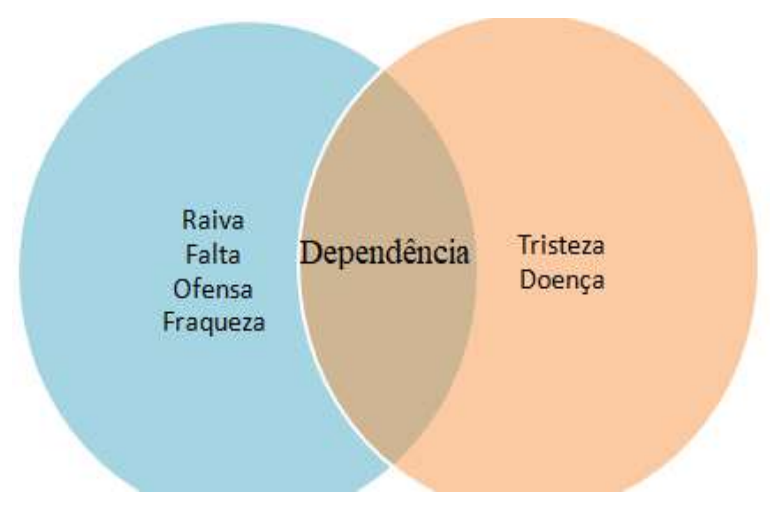

Legenda: católico espírita. Fonte: Autores (2020).

Entre as denominações evangélicas histórica, pentecostal e neopentecostal, os pontos de conjunção podem ser observados em dois elementos: "destruição e "dependência" (Figura 3). A visão de "pecado" atrelada às drogas é fortemente empregada nesse grupo até os dias atuais, como também a noção de destruição causada pela "possessão demoníaca" que levou ao consumo dessas substâncias (Mariano et al., 2020).

Figura 3. Ponto de conjunção entre os grupos evangélicos (históricos, pentecostais e neopentecostais) com base nos prováveis núcleos centrais do termo indutor drogas. Rio de Janeiro, RJ, Brasil, 2020.

\section{Históricos}

Pentecostais

Neopentecostais

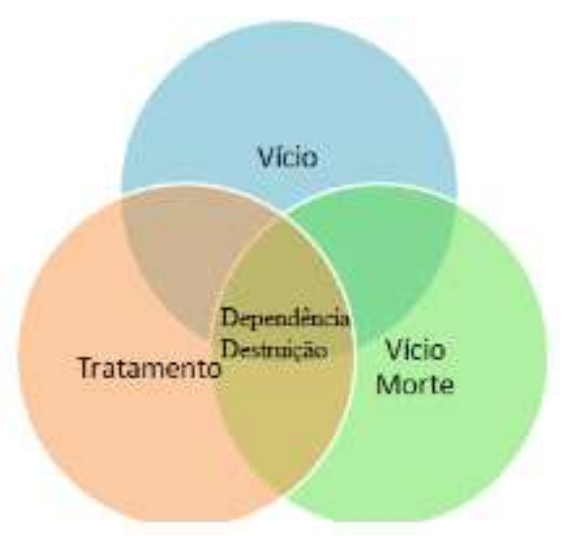

Fonte: Autores (2020).

As religiões de matriz africana participantes do estudo (umbanda e candomblé) apresentam como ponto de conjunção o elemento "dependência", igualmente observado na conjunção geral dos grupos religiosos, e o elemento "tristeza", reforçando-se o sentimento de caridade e de amor ao próximo, característico desse grupo religioso, principalmente no que diz respeito à umbanda. A representação dos pontos de conjunção entre essas religiões pode ser observada na Figura 4. 
Figura 2. Ponto de conjunção entre as religiões de matriz africana (umbanda e candomblé) com base nos prováveis núcleos centrais do termo indutor drogas. Rio de Janeiro, RJ, Brasil, 2020.

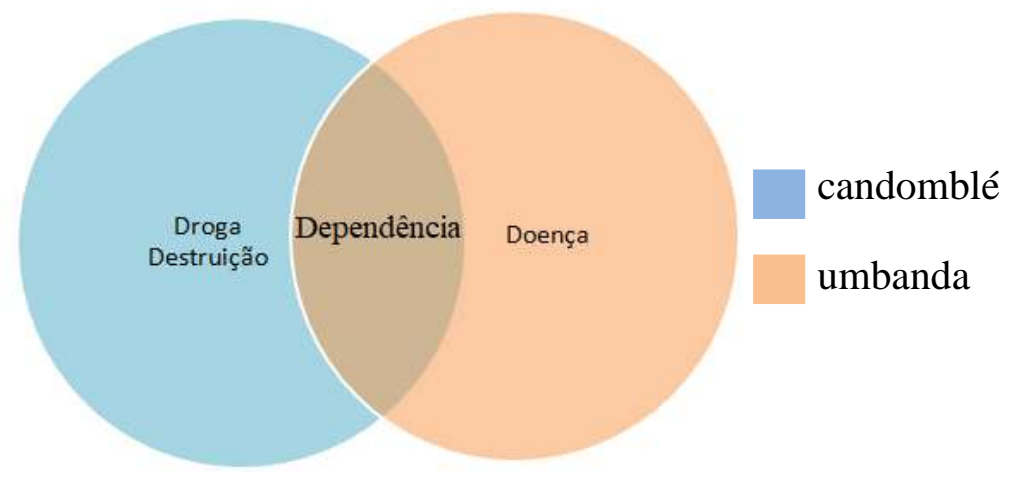

Fonte: Autores (2020).

\section{Discussão}

Assim, quando analisamos o conjunto de resultados, podemos observar que, de maneira geral, as representações sociais aqui encontradas perpassam cada religião, pelas doutrinas religiosas e pelo conhecimento dos seus fiéis sobre o assunto, de modo a entender as implicações para cada religião, a fim de se propor um cuidado em saúde e em enfermagem que vise alcançar o ser humano em sua plenitude como um ser biopsicossocial-espiritual.

Inicialmente, achávamos que se tratava de uma única representação social para todas as religiões participantes do estudo, no tocante às drogas psicoativas, tendo em vista que as palavras que formaram os núcleos centrais na análise prototípica se repetiram nos grupos religiosos. Esse resultado nos remete à noção de um grande sincretismo religioso entre as religiões pesquisadas.

O sincretismo religioso no Brasil é um fenômeno social complexo que surgiu com a chegada dos portugueses ao território brasileiro, impondo sua religião, mas também sofrendo influência da religião dos povos que aqui viviam (Suriani, 2019). Para Valente (1977), o sincretismo é um processo multifacetado que propõe solucionar os conflitos e os problemas em um dado contexto cultural. Ainda segundo o autor, a lógica do sincretismo não é a separação dos elementos, mas sim o que os une.

No contexto de vida dos indivíduos, a religião se apresenta como peça fundamental para seu desenvolvimento como ser humano, uma vez que fornece artifícios para o enfrentamento de questões relacionadas à vida e os auxilia na decisão do melhor caminho a ser seguido. Assim, cada religião, a partir da sua doutrina e dos seus ensinamentos, dita regras e guia o indivíduo diariamente (Borges, Santos, \& Pinheiro, 2015).

Quanto maior o envolvimento do indivíduo em sua comunidade religiosa, maior será a influência da doutrina na sua vida, mudando seus hábitos e sua relação com o mundo ${ }^{17}$, uma vez que as doutrina religiosas ditam regras e hábitos que devem ser seguidos pelos seus fiéis.

Dentre todas as mudanças encontradas na definição de droga no decorrer da história, a definição que encontramos nos dias de hoje e que mais circula na sociedade pauta-se em uma definição normativa e fundamentada em conceitos biomédicos, o que corrobora uma representação carregada de elementos negativos, tendo em vista que a área biomédica repreende veementemente o uso dessa substância e utiliza como justificativa as consequências do uso.

Outro fator que pode justificar o surgimento de muitos elementos de conotação negativa na representação das drogas para grupos religiosos é a maneira como são vinculadas informações a respeito das drogas nas mídias sociais, o próprio Ministério da Saúde vem intensificando campanhas que tratam das consequências do uso das drogas, sobretudo no que diz respeito ao crack e à adolescência (Guimarães, Rohlfs, Baêta, \& Santos, 2019). É sabido que a mídia tem um importante papel 
na construção das representações sociais, esse fato foi abordado e é discutido até hoje por teóricos da área. A mídia é um fator de determinação das representações, assim como no pensamento e na construção da realidade social (Guimarães et al., 2019).

Nessa perspectiva, a doutrina religiosa, a exemplo da como a mídia também colabora para que tenhamos uma representação das drogas carregada de elementos negativos, pois a doutrina dos grupos religiosos pertencentes ao estudo de maneira geral desencoraja o uso e ainda reforça a noção de afastamento do transcendental, após o seu uso de maneira abusiva.

Podemos observar, na representação das drogas para grupos religiosos, além dos elementos negativos dessa representação, o surgimento de elementos não ligados à substância e sim às consequências do seu uso, remetendo-nos, assim, à noção de que a substância, isoladamente, não apresenta uma representação e que só apresenta sentido social quando associada à figura do usuário, sugerindo, dessa forma, uma barreira indissociável entre as drogas e os seus usuários.

De posse desses resultados, podemos perceber que a representação da droga é multifacetada pelos grupos religiosos. Outro ponto importante a destacar é que em todas as religiões foi possível observar que existem artifícios para auxiliar o indivíduo a obter a cura e a libertação do consumo de drogas.

A respeito do cuidado em saúde e enfermagem, igualmente ao apontado em 1974, a Enfermagem acredita que o ser humano é biopssicosocial-espiritual, elevando assim, um cuidado para além da prática tecnicista (Gelain, 1974). Nessa perspectiva, para uma compreensão maior do cuidado de enfermagem, torna-se necessária a utilização de uma teoria prática de cuidar, baseada em dimensões que envolvam o corpo, a mente, a espiritualidade e a religiosidade dos indivíduos. Dessa forma, utilizamos a teoria do cuidado humano e das necessidades humanas básicas.

A assistência, levando-se em conta os fatores para além do espiritual, é benéfica não apenas para o paciente, mas também para a equipe de enfermagem, pois melhora a consciência espiritual e o contentamento no trabalho (Rosa, Hope, \& Matzo, 2018). Desse modo, fica evidente que é imprescindível a inserção da espiritualidade no cuidado de Enfermagem.

Nessa perspectiva, entendemos que o enfermeiro deve participar ativamente das atividades relacionadas à busca pela força interior do indivíduo. Essa busca por forças internas requer que o enfermeiro tenha a capacidade de saber o que é importante para si e respeite o significado para o outro (Heidari, Borujeni, Abyaneh, \& Rezaei, 2019).

A literatura atual, bem como também os resultados deste estudo deixam evidentes que os fatores que levam ao consumo de drogas e de álcool ligam-se, em sua maioria, a fatores intrínsecos ao paciente, sugerindo, assim, que a busca por força interior seria um fator indispensável para combater as questões internas que levam a esse consumo. Também foi possível observar em estudos que a religiosidade é fator de proteção para o consumo de drogas e de álcool (Glenn \& Pieper, 2019).

Assim, a Enfermagem deve entender o significado do consumo dessas substâncias para esses grupos religiosos de modo que possamos oferecer um cuidado que privilegie as diferenças entre eles.

\section{Considerações Finais}

A enfermagem é uma profissão ligada diretamente ao cuidar, e as características do seu trabalho favorecem um maior tempo de interação com o paciente, criando-se várias oportunidades para que se possa entender como a religiosidade e espiritualidade influenciam na vida de cada um, de modo a utilizar-se de ferramentas espirituais no cuidar para fortalecer não só o cliente, como também o profissional.

É sabido que a religiosidade se torna um fator de proteção para a utilização de drogas, como também já é de conhecimento que diversos fatores são predisponentes ao consumo, e a maioria deles refere-se a fatores emocionais. Dessa forma, utilizar-se de ferramentas religiosas e espirituais no tratamento do indivíduo, respeitando sua crença religiosa, visa não só melhorar a autoestima do paciente, mas também a um fortalecimento interior, a um fortalecimento espiritual que é capaz de auxiliá-lo a ficar livre das drogas. 
Durante a realização do estudo, ficou evidente que existe a necessidade da realização de estudos não apenas voltados à temática da espiritualidade no cuidar, mas que contemplem os aspectos particulares presentes em cada grupo religioso.

Em relação às práticas de saúde, fica evidente a existência de diversos fatores capazes de interferir no binômio saúdedoença, dentre os quais podemos elencar: fatores sociais, psicológicos e espirituais. Assim, os profissionais de saúde devem desenvolver artifícios capazes de contemplar as diversas áreas da vida dos indivíduos. Dessa forma, as questões religiosas e espirituais também devem ser empregadas como ferramenta de suporte ao cuidado.

\section{Referências}

Alves, J., Cavenaghi, S., Barros, L., \& Carvalho, A. (2017). Distribuição espacial da transição religiosa no Brasil. Tempo Social, 29(2), 215-242. https://doi.org/10.11606/0103-2070.ts.2017.112180.

Barbosa, D. J., Tosoli, A.M.G., Soares, G. O., \& Paes, L.S. (2018). Religiosidade e espiritualidade como ferramenta de apoio para o tratamento de usuários de drogas psicoativas. Pró-Universus, 9(2), 17-23. Recuperado de http://editora.universidadedevassouras.edu.br/index.php/RPU/article/view/1432.

Borges, M. S., Santos, M. B. C., \& Pinheiro, T.G. (2015). Representações sociais sobre religião e espiritualidade. Rev. Bras. Enferm, 68(4), 609-616. https://doi.org/10.1590/0034-7167.2015680406i.

Braga, C. Argumentos para utopias da realidade e a experiência da reforma psiquiátrica brasileira. (2020). Saúde e Sociedade, 29(3), 1-11. doi.org/10.1590/s0104-12902020190054

Brasil. (2010). IBGE. Censo Demográfico Populacional do Brasil nos últimos 10 anos. www.ibge.gov.br.

Castaneda, L. (2019). O Cuidado em Saúde e o Modelo Biopsicossocial: apreender para agir. CoDAS, 31(5), 1-2. https://doi.org/10.1590/2317$1782 / 20192018312$.

Conselho Nacional de Saúde. (2016). Resolução nº 510/2016. http://conselho.saude.gov.br/resolucoes/2016/Reso510.pdf.

Conselho Nacional de Saúde. (2012). Resolução no 466/12. http://bvsms.saude.gov.br/bvs/saudelegis/cns/2013/res0466_12_12_2012.html.

Farias Filho, J., Marchisotti, G., Maggessi, K., \& Miranda Junior, H. (2018). Método de pesquisa misto para identificação do problema de pesquisa. Conhecimento \& Diversidade,10(22), 88-102.DOI:10.18316/rcd.v10i22.5155.

Gelain, I. (1974). Necessidade psíco espiritual do paciente. Rev. Bras. Enferm, 27(3), 280-289. https://doi.org/10.1590/0034-716719740003000006.

Glenn, C. T., \& Pieper, B. 2019. Forgiveness and Spiritual Distress: Implications for Nursing. Journal of Christian Nursing, 36(3):185-189. https://doi.org/ 0.1097/CNJ.0000000000000613.

Guimarães, R., Rohlfs, D., Baêta, K., \& Santos, R. Estabelecimento de agentes e atividades ocupacionais carcinogênicas prioritárias para a vigilância em saúde no Brasil. (2019). Revista Brasileira de Medicina do Trabalho,17(2), 254-259. https://doi.org/ 10.5327/Z1679443520190289.

Heidari, M., Borujeni, M. G., Abyaneh, S. K., \& Rezaei, P. (2019). The Effect of Spiritual Care on Perceived Stress and Mental Health Among the Elderlies Living in Nursing Home. Journal of Religion and Health, 58(4), 1328-1339. https://doi.org/10.1007/s10943-019-0072-1

Juruena, M. F. (2017). O Diagnóstico dos transtornos mentais. Medicina, 50(supl.1), 1-2. https://doi.org/10.11606/issn.2176-7262.v50isupl1.p1-2.

Mariano, I., Oliveira. C., \& Babachinas, I. (2020). Percepções dos fatores que influenciam o uso de substâncias psicoativas em um centro de atenção psicossocial. Cadernos de Cultura e Ciência, 18(2), 46-61. http://periodicos.urca.br/ojs/index.php/cadernos/article/view/2064.

Moscovici, S. (2001) Representações sociais: um domínio em expansão. In: Jodelet, D. (org.). As representações sociais. Rio de Janeiro: UERJ, $2001.17-44$.

Rosa, W., Hope, S., \& Matzo, M. (2018). Palliative Nursing and Sacred Medicine: A Holistic Stance on Entheogens, Healing, and Spiritual Care. Journal of Holistic Nursing, 37(1), 100-106. https://doi.org/10.1177/0898010118770302.

Richter Reimer, I., \& Lemos, C. (2020). Apresentação religião, espiritualidade e saúde. Revista Caminhos - Revista de Ciências da Religião, 18(1), 4-12. http://dx.doi.org/10.18224/cam.v18i1.8061.

Silva, C. Relatório Mundial sobre drogas. (2012). Conjuntura Global, 1(1).

Suriani, 1. R. (2019). A formação das religiões afro-brasileiras: A interferência do sincretismo religioso. Sacrilegens, 16(1), 222-232. https://doi.org/10.34019/2237-6151.2019.v16.28835

Teixeira, M. B., Engstrom, E. M., \& Ribeiro, J. M. (2017). Revisão sistemática da literatura sobre crack: análise do seu uso prejudicial nas dimensões individual e contextual. Saúde em Debate, 41(112), 311-330. doi.org/10.1590/0103-1104201711225.

Valente, W. (1977). Sincretismo religioso afro-brasileiro. Companhia Editora Nacional. 